This item was submitted to Loughborough's Research Repository by the author.

Items in Figshare are protected by copyright, with all rights reserved, unless otherwise indicated.

\title{
Design and analysis of PID and Fuzzy-PID controller for voltage control of DC microgrid
}

PLEASE CITE THE PUBLISHED VERSION

http://dx.doi.org/10.1109/ISGT-Asia.2015.7387019

PUBLISHER

(C) IEEE

VERSION

AM (Accepted Manuscript)

\section{PUBLISHER STATEMENT}

This work is made available according to the conditions of the Creative Commons Attribution-NonCommercialNoDerivatives 4.0 International (CC BY-NC-ND 4.0) licence. Full details of this licence are available at: https://creativecommons.org/licenses/by-nc-nd/4.0/

\section{LICENCE}

CC BY-NC-ND 4.0

\section{REPOSITORY RECORD}

Chauhan, Rajeev Kumar, Bharat Singh Rajpurohi, R.E. Hebner, Sri Niwas Singh, and Francisco M. GonzalezLongatt. 2019. "Design and Analysis of PID and Fuzzy-pid Controller for Voltage Control of DC Microgrid". figshare. https://hdl.handle.net/2134/20517. 


\section{Design and Analysis of PID and Fuzzy-PID Controller for Voltage Control of DC Microgrid}

\author{
R. K. Chauhan and B. S. Rajpurohit \\ School of Computing \& Electrical Engg. \\ Indian Institute of Technology Mandi \\ Mandi, India \\ rajeevchr_nitj@yahoo.com \\ bsr@iitmandi.ac.in
}

\author{
R. E. Hebner \\ Center for \\ Electromechanics \\ University of Texas \\ Austin, USA \\ r.hebner@cem.utexas.edu
}

\author{
S. N. Singh \\ Deptt. Of Electrical \\ Engg. \\ IIT Kanpur \\ Kanpur, India \\ snsingh@iitk.ac.in
}

\author{
F. M. G. Longatt \\ Deptt. Of Electrical Engg. \\ University of \\ Loughborough, \\ Loughborough, UK \\ fglongatt@hotmail.co
}

\begin{abstract}
DC microgrids are desired to provide the electricity for the remote areas which are far from the main grid. The microgrid creates the open horizontal environment to interconnect the distributed generation especially photovoltaic (PV). The stochastic nature of the PV output power introduces the large fluctuations of the power and voltage in the microgrid and forced to introduce the controller for voltage stability. There are many control strategies to control the voltage of a DC microgrid in the literature. In this paper the proportionalintegral-derivative (PID) and fuzzy logic PID (FL-PID) controller has been designed and compared in term of performance. Performance measures like maximum overshoot and settling time of FL-PID compared with the PID proved that the former is better controller. The controllers are designed and simulated in the MATLAB programming environment. The controllers has been tested for the real time data obtained from Pecan Street Project, University of Texas at Austin USA.
\end{abstract}

Index Terms-- DC microgrids, controller, PID, fuzzy PID, distributed generation, distributed load, linear, nonlinear.

\section{INTRODUCTION}

The interest in the DC distribution system has increased during last few years. The concept of microgrid is well presented in literature [1-4], in which different types of microgrid units such as AC, hybrid (AC and DC) have been discussed. The advanced low voltage direct current (LVDC) distribution system is going to be used for the residential and commercial purposes [5-7]. However, during the comparison of $\mathrm{AC}$ and $\mathrm{DC}$ distribution system there is always a question raised about the maintenance and control of the specified grid voltage. There is a need to control voltage for power balance in the bus. Some studies have been carried out in the area of voltage control of the DC microgrid [8]. However most of them are related to the droop concept to regulate the grid voltage [9-10]. In a DC system, the grid voltage is affected when there is a change in demand and/or in generation. Therefore there is a need of good control mechanism to control the voltage of DC microgrid.
Few controlling schemes for the line currents compensation in the DC bus using the conventional controllers are given in literature [11-14]. Generally PI controllers are used to control the voltage of DC bus [15]. These controllers require accurate mathematical models. Due to functional and structure simplicity PID controllers are used most in industrial applications [16]. For first and second order systems, the PID controller gives good performance by tuning the parameters but for higher order systems the tuning become difficult. The performances of the PI and PID controllers is affected by the operating conditions of any system i.e. their performance can be degrades by the parameter variations, nonlinearity and load and generation changes [16]. On the other hand the fuzzy logic controller (FLC) has shown advantages over the conventional controllers. Fuzzy control requires the expert knowledge, experience and decision making.

Over recent years FLC are used for various applications due to their less complicated mathematics and effectiveness to input changes [17-20]. The fuzzy controllers are knowledge based (which is acquired by the engineer to control the plant) not model based as conventional controllers. The FLC creates a nonlinear relation between the system input and output. These controllers can be easily tuned to get the desired performance of the system with few mathematical complications. The conventional PID controller is based on the input error, integral of error and derivative of the error. Combining this with fuzzy logic the three parameters can be controlled by knowledge-based experience. An observer can observe the particular rate of change in error with fuzzy base PID controller without undergoing into a mathematical model.

A dynamic action is taken over the time because the differentiation and integration changes with time and depends on the past history. For providing the extra flexibility with past and future time some fuzzy-logic-based PID have been described [21-24]. In this system, there is a change in the power consumption from public utility (PU) due to variations in demand and PV power. This change leads to create fluctuations in the voltage of the DC microgrid. So there is a 
requirement of a control action to keep the voltage of DC microgrid at the reference voltage value i.e. 124 volt. In this paper, a voltage controller based on PID and fuzzy PID has been designed for DC microgrid. The fuzzy PID controller takes advantage of PID experiences and Fuzzy knowledge. The PID and FL-PID controllers are also compared based on the performance parameters.

\section{SYSTEM CONFIGURATION DC MICROGRID}

The layout of the voltage control system for the DC microgrid with distributed generation and load is shown in Fig. 1. The microgird consists of four homes with PV captive power plant and PU. There is a PV plant of $5 \mathrm{~kW}, 4.5 \mathrm{~kW}$, $4.75 \mathrm{~kW}$ and $6.5 \mathrm{~kW}$ installed in home-1, home-2, home-3 and home-4 respectively. The maximum demands of home-1, home-2, home-3 and home-4 are $10.32 \mathrm{~kW}, 10.88 \mathrm{~kW}, 10.13$ $\mathrm{kW}$ and $6.49 \mathrm{~kW}$ respectively. The demand and PV power profile of four homes for a typical day is shown in Fig.2.

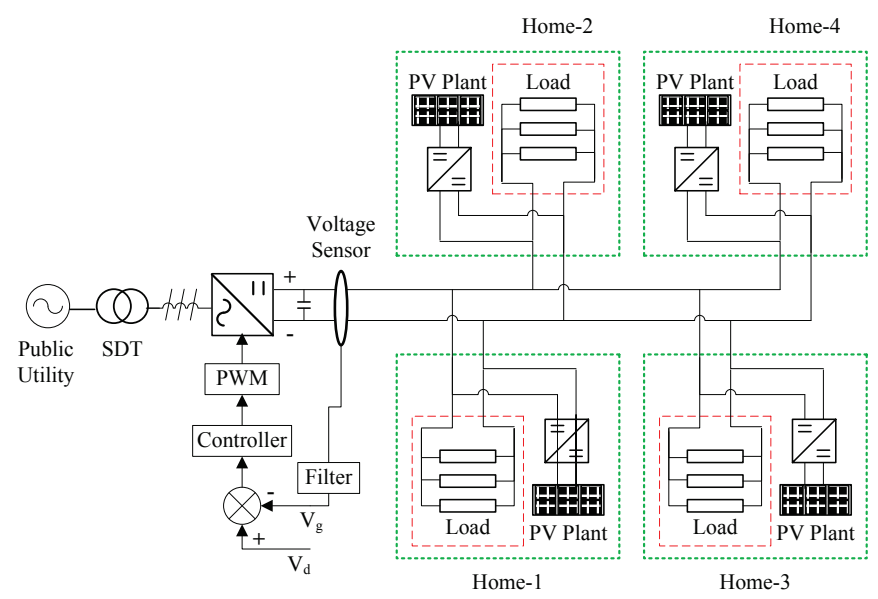

Figure 1. Layout of DC microgrid with distributed generation and load for voltage control

The data is obtained from by Peacan Street Project, University of Texas at Austin USA. The data is measured voltage, PV power and demands of home which is recorded at the every 15 minute for a typical day. The demand and the $\mathrm{PV}$ power varies with respect to the time. The $\mathrm{PU}$ is connected to the DC microgrid via AC-DC converter to balance the power in unbalance condition and absence of the PV power. The microgrid demand, PV power and power consumed from the PU with respect to the time are shown in Fig. 3. The demand and the PV generation are varying with respect to the time while the consumption from the $\mathrm{PU}$ depends on difference between the demand and the power generation by PV plants and varies with time.

The variation in the demand and PV power is the primary cause of variation in the microgrid voltage. The microgrid voltage varied with respect to the power fluctuations [25]. As the demand increases the microgrid voltage decreses below the reference voltage. The fluctuations in the microgrid voltage forced the intorduction of the controller to keep the microgrid voltage appropriately near the desired voltage and to make any required corrections as quickly as possible. The desired voltage is selected to be 124 volt. The real-time micorgrid voltage is measured by a voltage sensor as shown in Fig. 1.
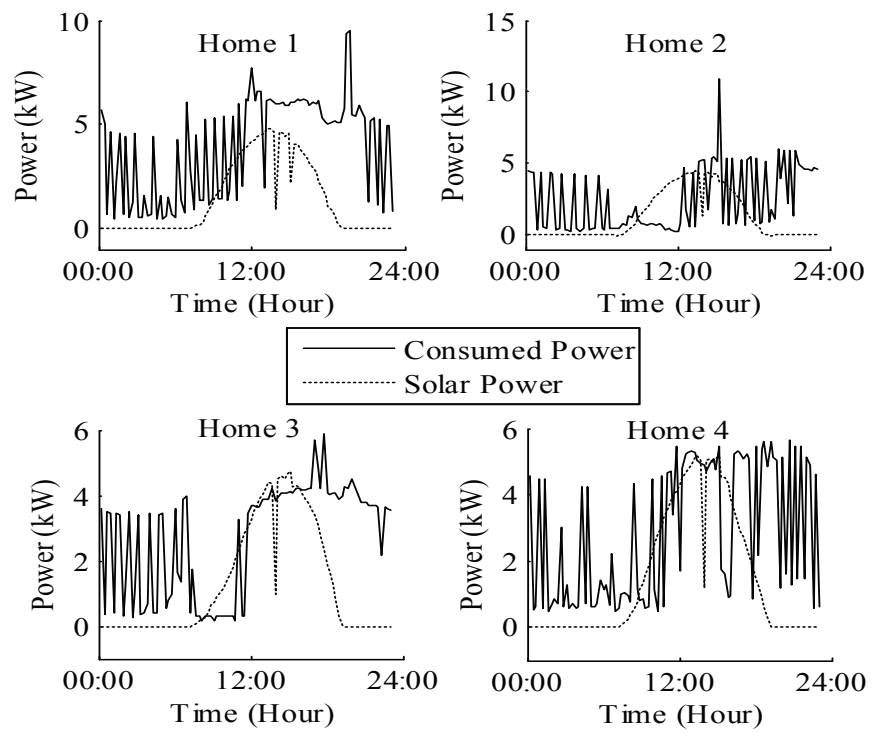

Figure 2. Demand and solar power profile for four home for typical day

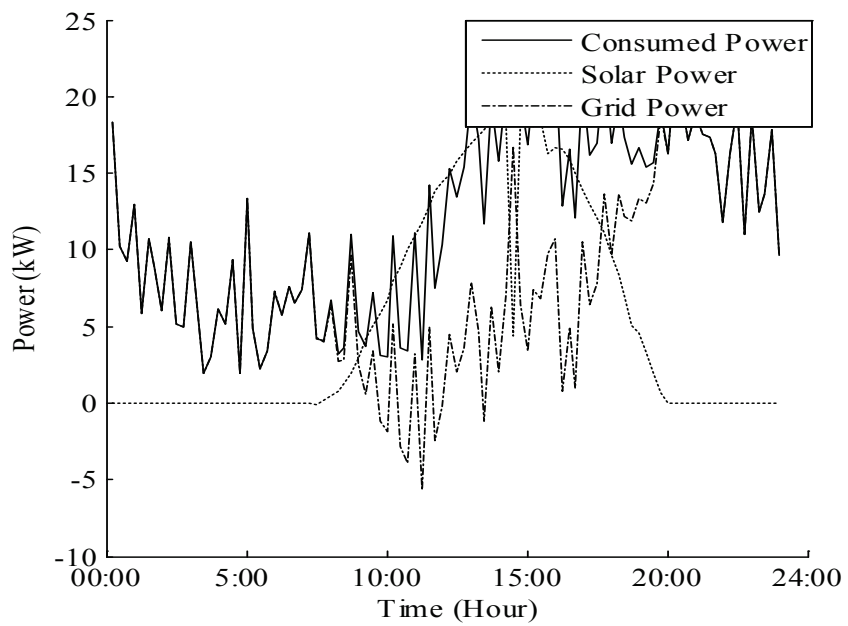

Figure 3. Total demand and solar power in four with public utility

In section II there is description and design of the PID controller for the voltage control of DC microgrid. In section III, a FL-PID controller is designed for the same system with the description of the fuzzy rule and membership function is used. Section IV is showing the simulation results obtained from both the controllers and their comparison. Finally, section $\mathrm{V}$ concludes the paper.

\section{DESIGN OF PID CONTROLleR}

The performance of the proportional integral derivative (PID) controller can be analyzed by three factors: the propositional gain $\left(K_{p}\right)$, integral gain $\left(K_{i}\right)$ and derivative gain $\left(K_{d}\right)$. The unit feedback closed loop control system for voltage control of DC microgrid with PID controller is shown in Fig. 4. The error signal $(e)$ signal is the difference of the measured voltage $\left(V_{o}\right)$ and desired voltage $\left(V_{d}\right)$ and amplified 
by the controller.The controller output makes the necessary changes to the PWM signal to reduce the error by changing the PU power sharing via AC-DC converter with DC microgrid. The magnitude and polarity of the resulting error signal would be directly related to the difference between $V_{o}$ and $V_{d}$ of the microgrid.

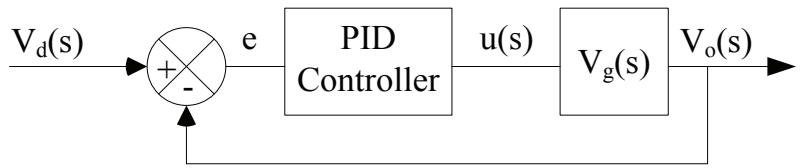

Figure 4. Layout of voltage control system with PID controller for DC microgid

The output of the PID controller can be expressed as

$u(s)=K_{p} e(s)+K_{i} \frac{1}{S} e(s)+K_{d} S e(s)$

and the transfer function can be expressed as:

$G(s)=\frac{u(s)}{e(s)}=K_{p}+K_{i} \frac{1}{S}+K_{d} S$

Where $e(s)=\left|V_{d}-V g\right|$ or $e(s)=\left|V_{d}-V_{o}\right|$

The $K_{p}$ will reduce the rise time, but it will never eliminate the steady-state error. The $K_{i}$ will eliminate the steady-state error, but it may make the transient response worse. The $K_{d}$ will have the effect of increasing the stability of the system, reducing the overshoot, and improving the transient response.

\section{DESIGN OF FUZZY LOGIC-PID CONTROLlER}

The variables of any system can be represented as the members of a set in the fuzzy logic set theory. The fuzzy system can break up in to three sets as shown in Fig. 5. The fuzzy controller having fuzzy and PID block. The fuzzy block is divided up into three blocks the first block is the fuzzification: converts the crisp input to the linguistic variable. The fuzzification is a knowledge-based task. The input variables are to be mapped on fuzzy sets. The next block is the inference is a rule-based task created by experts' knowledge. Deffuzzification converts the linguistic variable back to a crisp value. In the Fig. $5, V_{f_{o}}$ is the output voltage, $u_{f}$ is the output obtained from the FL-PID which is input to the plant and $e$ is the error between $V_{f o}$ and $V_{g}$. The linguistic change can be made by taking the input variables in three terms. The linguistic variables defined here related to the time-varying fuzzy-controller inputs. As in Fig. 6, there are two inputs: "DC grid voltage error" described as $e(t)$. "Integral of DC grid voltage error" described as $\int e(t)$. Suppose the DC voltage can be expressed as linguistic variables as seven fuzzy subsets NB (Negative Big), NM (Negative Medium), NS (Negative Small), ZE (Zero), PB seven fuzzy NB(Negative Large), NM (Negative Medium), NS (Negative Small), Z (Zero), PS (Positive Small), PM (Positive Medium) and PB (Positive Big). The number values are to be chosen as the linguistic variables as -3 for $\mathrm{NB},-2$ for NM, -1 for NS, 0 for Z, 1 for PS, 2 for PM, and 3 for PB. In this simple way, the numeric values are just for representation and for the designing of the fuzzy controller, these values do not represent the true values of the DC voltage. Based on the linguistic variables there is a need to create a "rule base" which is based on the knowledge of the conditions for controlling the DC microgrid voltage. Here the PID parameters are adjusted for the best control of DC microgrid voltage by using the feedback obtained from the voltage error itself.

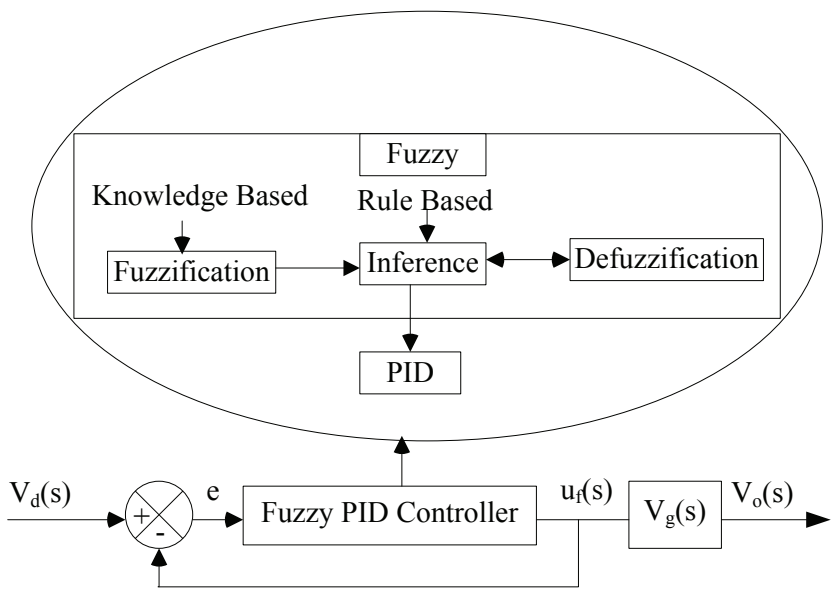

Figure 5. Layout of voltage control system with fuzzy-PID controller for DC microgid

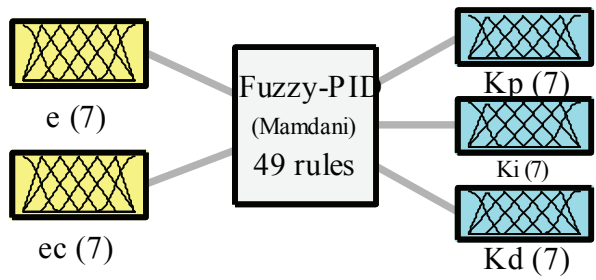

System fuzzy-pid: 2 inputs, 3 outputs, 49 rules

Figure 6. Membership function for fuzzy PID

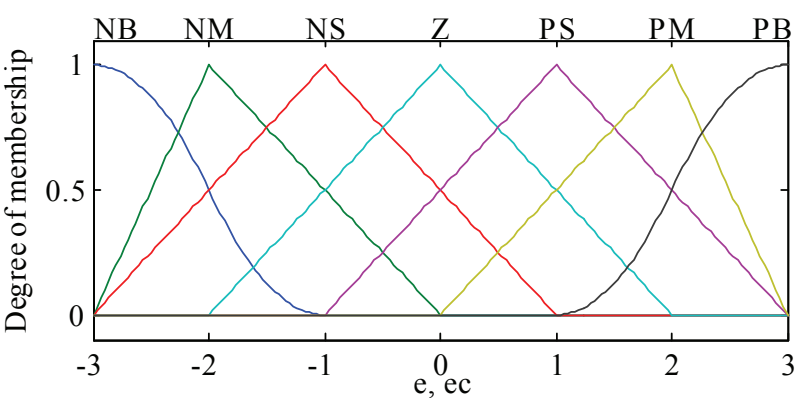

Figure 7. Membership function for FL-PID inputs error and change in error

Membership functions used for the input and output variables are shown in Fig.6. Membership function obtained for input variable error $(e)$ and change in error $(e c)$ is shown in Fig. 7 and for output variables $K_{p}, K_{i}$, and $K_{d}$ are shown in Fig. 8. 


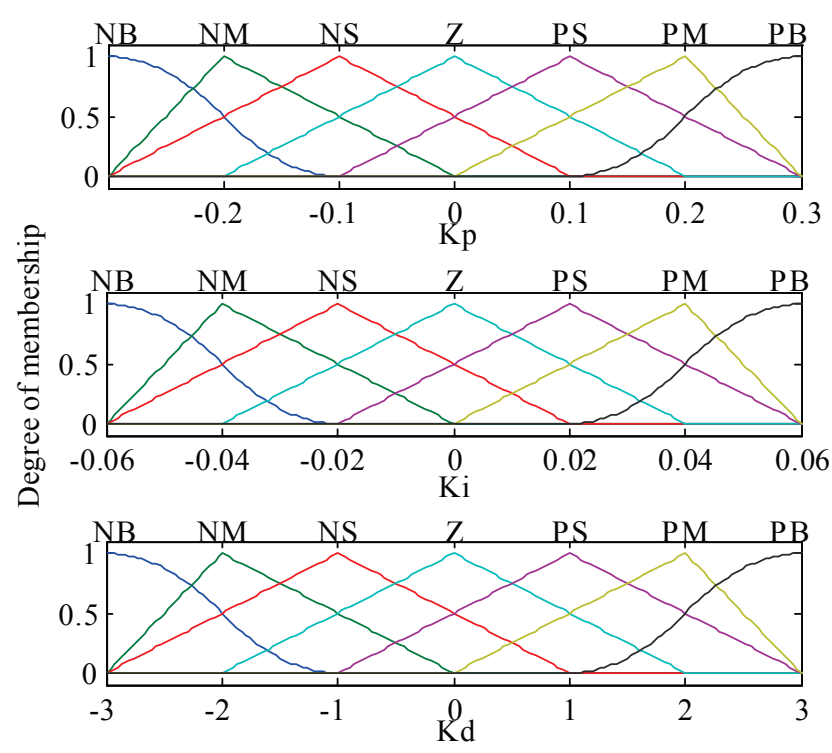

Figure 8. Membership function for FL-PID outputs $K p, K i$, and $K d$ TABLE I. Fuzzy Rules For Kp

\begin{tabular}{|c|c|c|c|c|c|c|c|}
\hline $\mathrm{ec}^{\mathrm{e}}$ & NB & NM & NS & $\mathbf{Z}$ & PS & PM & PB \\
\hline NB & NB & NB & NB & NM & NM & Z & Z \\
\hline NM & NB & $\mathrm{NB}$ & $\mathrm{NM}$ & $\mathrm{NM}$ & NS & Z & Z \\
\hline NS & NM & NM & NS & NS & Z & PS & PS \\
\hline $\mathbf{Z}$ & NM & NS & NS & $\mathrm{Z}$ & PS & PS & $\mathrm{PM}$ \\
\hline PS & NS & NS & Z & PS & PS & NM & PM \\
\hline PM & $\mathrm{Z}$ & $\mathrm{Z}$ & PS & $\mathrm{PM}$ & $\mathrm{PM}$ & $\mathrm{PB}$ & $\mathrm{PB}$ \\
\hline PB & Z & Z & PS & PM & PB & $\mathrm{PB}$ & PB \\
\hline
\end{tabular}

\begin{tabular}{|c|c|c|c|c|c|c|c|}
\hline ec & NB & NM & NS & $\mathbf{Z}$ & PS & PM & PB \\
\hline NB & PB & PB & PM & PM & PS & PS & $Z$ \\
\hline NM & PB & PB & PM & PM & PS & $Z$ & $Z$ \\
\hline NS & PM & PM & PM & PS & $Z$ & NS & NM \\
\hline Z & PM & PS & PS & Z & NS & NM & NM \\
\hline PS & PS & PS & Z & NS & NS & NM & NM \\
\hline PM & $Z$ & $Z$ & NS & NM & NM & NM & NB \\
\hline PB & Z & NS & NS & NM & NM & NB & NB \\
\hline
\end{tabular}

TABLE III.

Fuzzy Rules For $\mathrm{K}_{\mathrm{d}}$

\begin{tabular}{|c|c|c|c|c|c|c|c|}
\hline ec & NB & NM & NS & $\mathbf{Z}$ & PS & PM & PB \\
\hline NB & PS & PS & Z & Z & Z & PB & PB \\
\hline NM & NS & NS & NS & NS & Z & PS & PM \\
\hline NS & NB & NB & NM & NS & Z & PS & PM \\
\hline Z & NB & NM & NM & NS & $Z$ & PS & PM \\
\hline PS & NB & NM & NS & NS & $Z$ & PS & PS \\
\hline PM & NM & NS & NS & NS & Z & PS & PS \\
\hline PB & PS & $Z$ & $Z$ & $Z$ & $Z$ & PB & PS \\
\hline
\end{tabular}

As we have two inputs and seven linguistic values so there are $(7)^{2}=49$ rules for adjusting the every PID parameter. The rules for representing the output variables $K_{p}$, $K_{i}$, and $K_{d}$ are shown in tables I-III respectively.

\section{Simulation Results}

The assess the control of the voltage of the microgrid system, the system shown in Fig. 1 is modeled. The real time simulations for the controllers are done in the MALAB $\mathrm{m}$-file environment. The real-time simulation is structured to provide results that would be expected to be obtained from the hardware version of the system. The performance of the voltage controllers are tested for the complete typical day with varying load conditions. Results obtained from both the controllers viz. PID controller and FL-PID controller are shown in the following analysis. The PID controller response to control the voltage of DC microgrid with the fluctuations in microgrid real power due to the change in deamnd and PV power is shown in Fig. 9. The controlled voltage approaches its desired value 124 volt (shown with dotted line the plot) and its measured value (which is continuous line in the plot) with the help of PID controller (the response is shown with

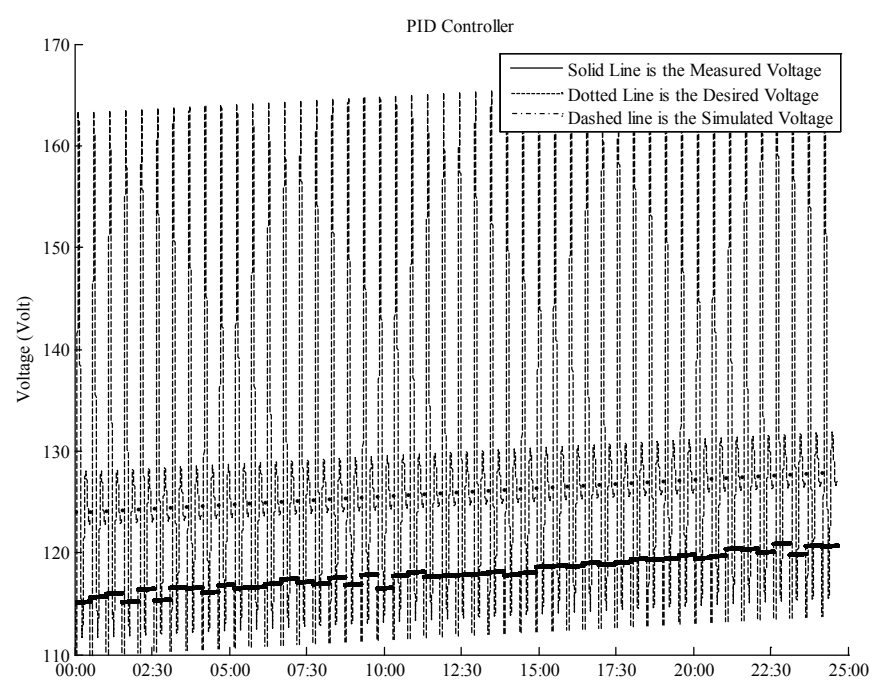

Figure 9. DC microgrid voltage response with PID Controller

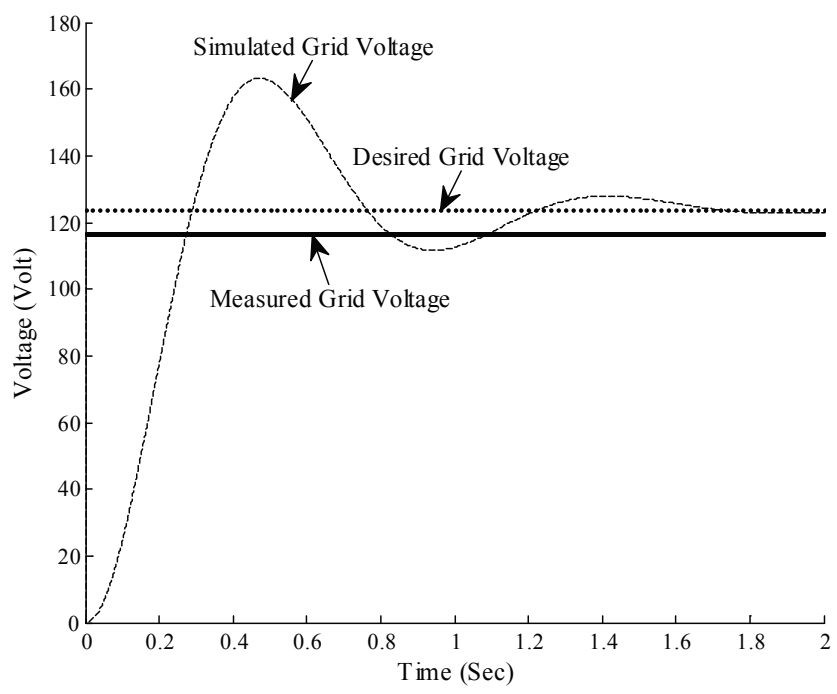

Figure 10. PID controller response to voltage control of the DC microgrid 
dashed line in the plot). In this case also the data is taken for every $30 \mathrm{~min}$ of a typical day.

The FL-PID controller response for controlling the voltage of DC microgrid with the fluctuations in microgrid real power due to the change in demand and PV power is shown in Fig. 11. The controlled voltage approaches to its desired value 124 volt (shown with dotted line the plot) and its measured value (which is continuous line in the plot) with the help of FL-PID controller (the response is shown with dashed line in the plot).

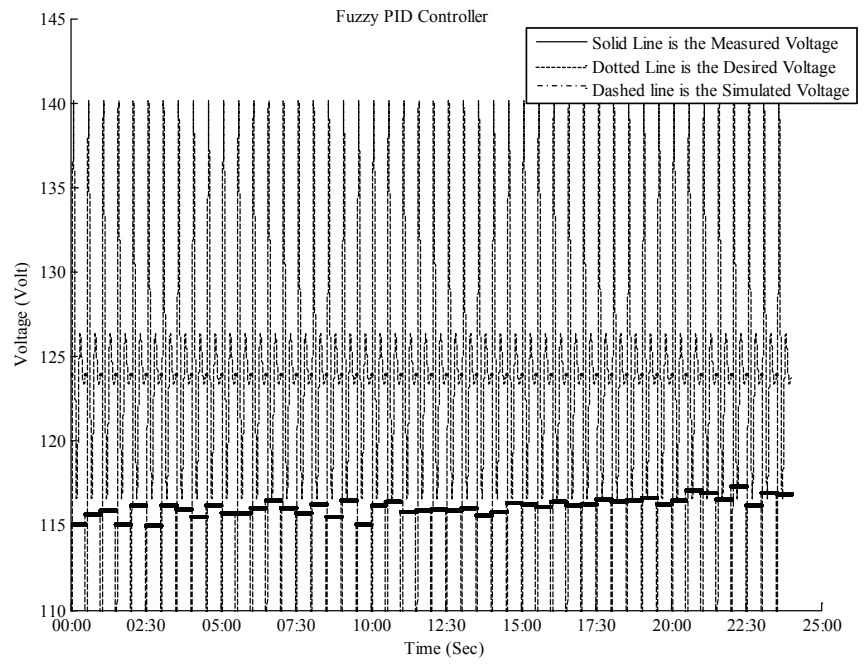

Figure 11. DC microgrid voltage response with FL-PID Controller

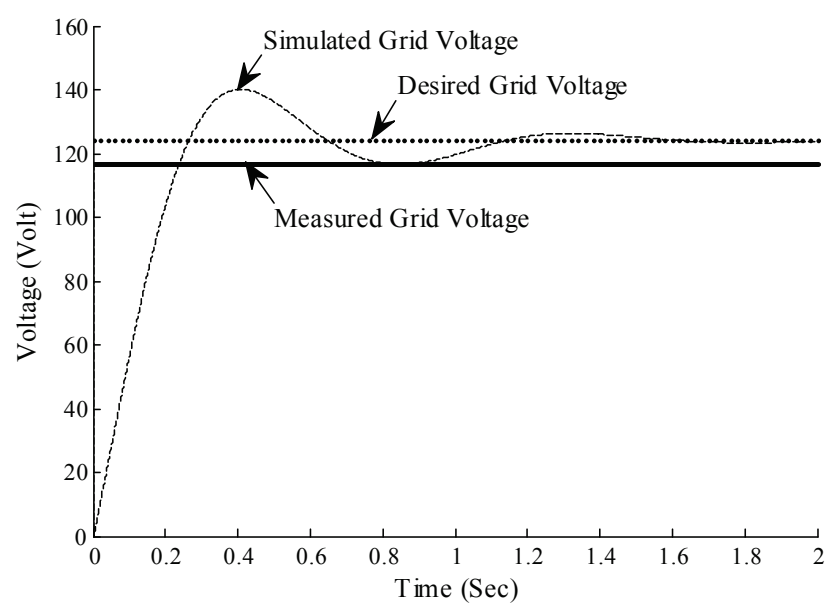

Figure 12. FL-PID controller response to voltage control of the DC microgrid

The time response parameters of PID and FL-PID controller are shown in table IV. The rise time for the FL-PID is higher than PID. The steady state error for FL-PID controller is small as compared to PID controller. It means the FL-PID is better than PID. The overshoot is case of FLPID is very less, In case of PID the peak voltage around 162 volts i.e. around 38 volts more than the desired level however in case of FL-PID this value is nearly 140 volts i.e. 16 volts more than the desired level voltage. So the percentage overshoot is very less in case of FL-PID controller in comparison to the PID controller. The overshoot is lower for FL-PID than PID which proved that the FL-PID is more stable than the PID and leaves the small voltage fluctuations on the microgrid. While the small settling time of FL-PID makes it faster than the PID. Further peak time is smaller for FL-PID with respect to the PID controller. It means the response of FL-PID controller response is reached at maximum overshot faster than the response PID controller.

TABLE IV. TIME RESPONSE OF THE DESIGNED CONTROLLER FOR DC MICROGRID VOLTAGE

\begin{tabular}{|c|c|c|c|c|c|}
\hline \multirow{2}{*}{$\begin{array}{c}\text { Controller } \\
\text { Type }\end{array}$} & \multicolumn{5}{|c|}{ Time Response Parameters } \\
\cline { 2 - 6 } & $\begin{array}{c}\text { Rise } \\
\text { time } \\
\text { (Sec) }\end{array}$ & $\begin{array}{c}\text { Settling } \\
\text { time } \\
\text { (Sec) }\end{array}$ & $\begin{array}{c}\text { Over- } \\
\text { shoot (\%) }\end{array}$ & $\begin{array}{c}\text { Peak } \\
\text { time } \\
\text { (Sec) }\end{array}$ & $\begin{array}{c}\text { Steady } \\
\text { state error } \\
(\%)\end{array}$ \\
\hline PID & 0.0148 & 1.6091 & 0.326 & 0.47 & 0.9231 \\
\hline FL-PID & 0.0264 & 1.3609 & 0.132 & 0.41 & 0.2325 \\
\hline
\end{tabular}

\section{CONCLUSIONS}

The DC microgrids are promising approach to provide the electricity for the areas far from the main grid. The DC bus voltage stability is an issue and challenge in DC microgrid for normal operation. In this paper, PID and fuzzy logic PID controller has been designed for maintaining the DC bus voltage. Overall analysis of PID and FL-PID controller proved that the FL-PID is superior and better for voltage control of the DC microgrid studied. The fluctuation in the DC microgrid voltage with the fluctuations in microgrid power due to variation in demand and PV power of homes has been explained with the help of simulation for a typical day. The paper has demonstrated the potential of fuzzy control over other conventional control.

\section{ACKNOWLEDGEMENT}

Authors are thankful to Center for Electromechanics, University of Texas at Austin for providing data from "Pecan Street Project". Authors are also thankful to DST-UKIERI for financial support.

\section{REFERENCES}

[1] N. D. Hatziargyriou, H. Asano, H. R. Iravani, and C. Marnay, "Microgrids," IEEE Power Energy Mag., vol.5, no.4, pp.78-94, Jul. 2007.

[2] R. K. Chauhan, B. S. Rajpurohit, S. N. Singh and F. M. G.Longatt, "DC Grid Interconnection for Conversion Losses and Cost Optimization", Renewable Energy Integration: Challenges and Solutions, Springer book, ch. 14, pp 327-345, Sep. 2013.

[3] N. Pogaku, M. Prodanovic, and T. C. Green, "Modeling, analysis and testing of autonomous operation of an inverter-based microgrid," IEEE Trans. Power Electron, vol.22, no.2, pp.613-625, Mar. 2007.

[4] R. K. Chauhan, B. S. Rajpurohit, and N. M. Pindoriya, "DC power distribution system for rural applications" in proc. $20128^{\text {th }}$ National conference on Indian energy sector, AMA, Ahmedabad, pp.108-112. 
[5] R. K. Chauhan, B. S. Rajpurohit, R. E. Hebner, S. N. Singh, and F. M. Gonzalez-Longatt, "Voltage Standardization of DC Distribution System for Residential Buildings," Journal of Clean Energy Technologies, vol. 4, no.3, May 2016, pp. 167-172.

[6] J. M. Carrasco, L. G. Franquelo, J. T. Bialasiewiez, E. Galvan, E Guisado, M. M. Prats, J. I. Leon, and N. M. Alfonso, "Power-electronic systems for the grid integration of renewable energy sources: A survey," IEEE Trans. Power Electron, vol.53, no.4, pp.1002-1016, Jun. 2006.

[7] R. K. Chauhan, B. S. Rajpurohit, "DC Distribution System for energy efficient buildings," in proc. 2014 IEEE $18^{\text {th }}$ National Power System Conference, India, Dec. 18-20, 2014, pp.1-6.

[8] J. C. Choi, H. Y. Jeong, D. J. Won, S. J. Ahn and S. I. Moon, "Cooperative voltage control of distributed generation and grid connected converter in dc microgrid," Renewable Energy and Power Quality Journal, no.2, Mar. 2013.

[9] Y. Ito, Y. Zhongqing, and H Akagi, "DC microgrid based distribution power generation system," in proc. 2004 IEEE $4^{\text {th }}$ International Conference on Power Electronics and Motion Control, vol. 3, pp. 17401745.

[10]H. Kakigano, A. Nishino, and T. Ise, "Distribution voltage control for dc microgrid with fuzzy control and gain-scheduling control," in proc. 2011 IEEE $8^{\text {th }}$ International Conference on Power Electronics and ECCE Asia, pp. 254-263.

[11]B. Singh, A. Chandra, and K. Al-Haddad, "Computer-aided modeling and simulation of active power filters," Elect. Mach. and Power Syst., vol.27, no.11, pp.1227-1241, 1999.

[12]K. Chatterjee, B. G. Fernandes, and G. K. Dubey, "An instantaneous reactive volt-ampere compensator and harmonic suppressor system," IEEE Trans. Power Electron., vol. 14, no. 2, pp. 381-392, Mar. 1999.

[13]S. Jain, P. Agarwal, and H. O. Gupta, "Design simulation and experimental investigations on a shunt active power filter for harmonics and reactive power compensation," Elect. Power Compon. and Syst., vol. 32, no. 7, pp. 671-692, Jul. 2003.

[14]F. Blaabjerg, R. Teodorescu, M. Liserre, and A.V. Timbus, "Overview of control and grid synchronization for distributed power generation systems," IEEE Trans. Ind. Electron., vol. 55, no.3, pp. 1398-1411, Oct. 2006.

[15] S. Buso, L. Malesani, and P. Mattavelli, "Comparison of current control techniques for active power filter applications", IEEE Trans. Ind. Electron., vol.45, no.5, pp.722-729, Oct. 1998.

[16] M. Ho, and C. Lin, "PID controller design for robust performance," IEEE Trans. Automatic Control, vol. 48, no. 8, pp. 1404-1409, Aug. 2003.

[17] G. K. I. Mann, B. G. Hu, and R. G. Gosine, "Analysis of direct action fuzzy PID controllers structures," IEEE Trans. Syst. Man Cybern., vol. 29, no.3, pp.371-388, Jun. 1999.

[18]B. K. Bose, "Expert systems, fuzzy logic and neural network, applications in power electronics and motion control," in proc.1994 IEEE Piscataway, NJ: IEEE Press, ch. 11, pp. 1303 - 1323.

[19] V. S. C. Raviraj and P. C. Sen, "Comparative study of proportional integral, sliding mode, and fuzzy logic controllers for power converters," IEEE Trans. Ind. Appl., vol.33, no.2, pp. 518-524, Mar./Apr. 1997.

[20]C. C. Lee, "Fuzzy logic in control systems: fuzzy logic controller-part I", IEEE Trans. Syst. Man. Cybern., vol.20, no. 2, pp. 404-418, Mar/Apr 1990.

[21]K. Rajani and R. Pal Nikhil R., "A robust self-tuning scheme for PI and PD-type fuzzy controllers," IEEE Trans. Fuzzy Syst., vol.7, no.1, pp. 216, Feb. 1999.

[22]H. Baogang, G. K. I. Mann and R. G. Gosine, "New methodology for analytical and optimal design of fuzzy PID controllers", IEEE Trans. Fuzzy Syst., vol.7, no.5, pp.521-539, Oct. 1999.

[23]Z. W. Woo, H. Y. Chung and J. J. Lin, "A PID type fuzzy controller with self-tuning scaling factors," Fuzzy Sets and Syst., vol.115, no.2, pp. 321-326, Oct.2000.

[24] I. Pan, S. Das and A. Gupta, "Tuning of an optimal fuzzy PID controller with stochastic algorithms for networked control systems with random time delay," ISA Trans., vol.50, no.1, pp.28-36, Jan. 2011.

[25]D. Chen and L. Xu, "Autonomous de voltage control of a de microgrid with multiple slack terminals," IEEE Trans. power syst., vol.27, no.4, pp.1897-1905, Nov.2012.

\section{BIOGRAPHIES}

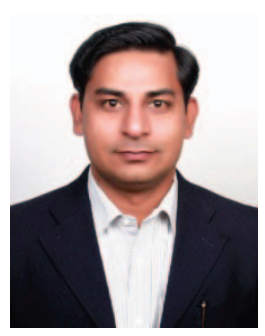

Rajeev Kumar Chauhan (M'10,SM' 15) graduated in Electrical Engineering from The Institutions of Engineers (India). He received his M. Tech degree in Control and Instrumentation Engineering from Dr. B. R. Ambedkar National Instiute of Technology Jalandhar, India. Presently, he is pursuing $\mathrm{Ph}$. D from School of Computing and Electrical Engineering, Indian Institute of Technology Mandi, India. His major field of interest included DC Microgrid, SCADA System, Industrial Automation and Control. $\mathrm{He}$ is the member of PES, IEEE, IAENG Hong Kong and ICASIT.

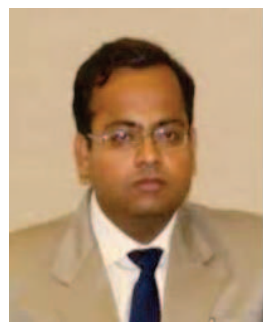

Bharat Singh Rajpurohit (M'09-SM'14) received M. Tech. from the Indian Institute of Technology Roorkee, India and Ph.D from Indian Institute of Technology Kanpur, India. Presently, he is working as Asst. Professor in the School of Computing and Electrical Engineering at Indian Institute of Technology Mandi, India. His research interests include power electronics and grid integration of renewable energy sources. He is a member of ISTE and IEEE.

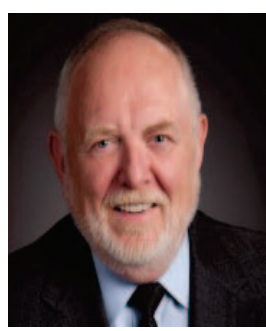

Robert E. Hebner (LF'93) is graduated in physics from the St. Mary's University, San Antonio, TX, Physics, BS, 1967. He received his $\mathrm{MS}$ and $\mathrm{PhD}$ from University of Missouri, Rolla, MO in 1969 and 1971 respectively. Dr. Hebner is the Director of the Center for Electromechanics at the University of Texas at Austin. He is also a past President of the IEEE Dielectrics and Electrical insulation Society and current vice president of the IEEE for Technical Activities. Before joining the University of Texas, he spent many years at the National Institute of Standards and Technology (NIST), culminating his time there as acting Director.

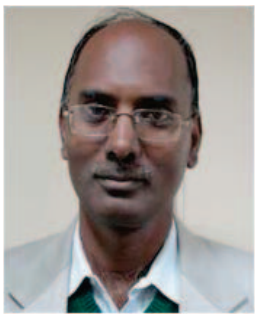

S. N. Singh (SM'02) received the Ph.D. degree in electrical engineering from the Indian Institute of Technology Kanpur, India, in 1995. He is currently a Professor with the Department of Electrical Engineering, Indian Institute of Technology Kanpur. His research interests include power system restructuring, FACTS, power system optimization and control, security analysis, and power system planning. Dr. Singh is a Fellow of the IETE, India, and the Institution of Engineers, India.

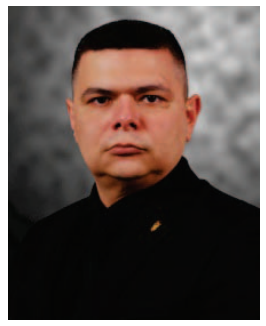

Francisco M. Gonzalez-Longatt (S'98-M'00SM'08) is currently a Lecturer in Electrical Power System at Electrical Power System en School of Electronic, Electrical and Systems Engineering en Loughborough University. His academic qualifications include first Class Electrical Engineering of Instituto Universitario Politécnico de la Fuerza Armada Nacional, Venezuela (1994), Master of Business Administration (Honors) of Universidad Bicentenaria de Aragua, Venezuela (1999) and PhD in Electrical Power Engineering from the Universidad Central de Venezuela (2008). He is member of IEEE, IET and CIGRE. His research interest includes innovative (operation/control) schemes to optimize the performance of future energy systems. 